negative (LTCD3+ TCR $\alpha \beta+$ CD4- CD8-) about $27 \%$ (control < $2.5 \%$ ). The study of FAS gene allowed the identification of a mutation in exon 9 .

Conclusion ALPS is an underestimated entity that must be considered in non malign lymphoproliferation, autoimmunity and expansion of an unusual population of a/B CD3+CD4-CD8- (double-negative $\mathrm{T}$ cells $>1 \%$ )

\section{A RARE CASE OF LANGDON DOWN SYNDROME WITH COMPLETE ENDOCARDIAL CUSHION DEFECT, TETRALOGY OF FALLOT, DEFICIENCY OF FACTOR VII}

doi:10.1136/archdischild-2012-302724.0515

${ }^{1} \mathrm{M}$ Militaru, ${ }^{2} \mathrm{~A}$ Maris. ${ }^{1}$ The Child and Mother Health Department, The Intermediate Care Unit; ${ }^{2}$ The Intermediate Care Unit, The Clinical Hospital for Children, University of Medicine and Pharmacy 'Iuliu Hatieganu', Cluj-Napoca, Romania

Aims We sought to summarize a very rare association between multiple rare incidence diseases in a patient with Langdon-Down syndrome and also to correctly document each pathology and use the best course of treatment.

Background Factor VII deficiency has an incidence of 1 in 500.000 reported cases. Complete endocardial cushion defect [ECD] occurs in $2 \%$ percent of all congenital heart defects. Additional cardiac abnormalities (persistent ductus arteriosus and tetralogy of Fallot [ToF]) may occur in 10\% of all ECD's. Associated defects are rare in children with Down syndrome.

Methods A 5 weeks old infant with a Down phenotype was admitted in the Intermediate Care Unit for severe tonic-clonic seizures and an unexplored heart murmur. A computed tomography scan revealed a massive hemorrhaging in the fronto-parieto-occipital left cerebral region. Trauma was excluded and the prothrombin time was prolonged with the activated partial trhomboplastin time normal so we sent a blood sample for the factor VII activity.

We performed an echocardiography.

A karyotype study was carried out.

\section{Results}

- Complete ECD with the common atrio-ventricular valve in dextroisomerism, left ventricle hypoplasia, associated with ToF.

- The factor VII activity showed a $2 \%$ activity level

- classical 21 trisomy

Conclusion We provided a good documentation of a very rare association between separate severe pathologies and we showed that when faced with a congenital malformative syndrome one should never stop looking for other abnormalities.

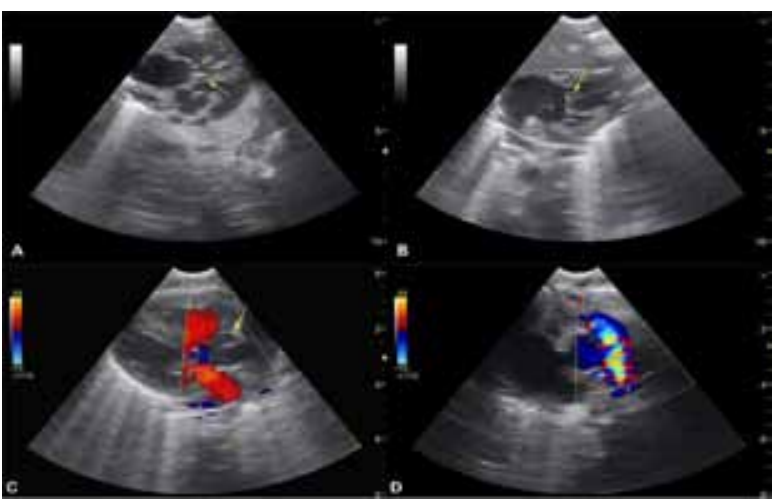

Abstract 515 Figure 1

A- subcostal view- the arrow points to the insertion of anterior left leaflet on a papillary muscle, the $X$ 's show a ventricula

B- subcostal view- the common AV valve and the atrial septal defect;

C- parasternal long axis- the over-riding aorta;

D- parasternal short axis- turbulent flow through the pulmonary valve (pulmonary artery stenosis)

\section{A VERY RARE CASE REPORT OF HERMANSKY-PUDLAK} SYNDROME TYPE II

doi:10.1136/archdischild-2012-302724.0516

${ }^{1} \mathrm{G}$ Karasu, ${ }^{2} \mathrm{M}$ Innalhan, ${ }^{2} \mathrm{~F}$ Yıldız, ${ }^{2} \mathrm{O}$ Temel, ${ }^{20}$ Arslan, ${ }^{2} \mathrm{M}$ Cengiz. ${ }^{1}$ Pediatric Hematology; 2Pediatrics, Zeynep Kamil Maternity and Children Diseases Training and Research State Hospital, Istanbul, Turkey

Introduction Hermansky-Pudlak syndrome type 2 (HPS-2) is a very rare multi-system disorder characterized by oculocutaneous albinism, reduced visual acuity, horizontal nystagmus, bleeding diathesis and recurrent infections due to neutropenia and impaired cytotoxic activity. HPS-2 is caused by mutations in the AP3B1 gene (5q14.1) and is transmitted in an autosomal recessive manner. The gene product is the Beta $3 \mathrm{~A}$ subunit of adaptor protein 3 (AP3), involved in vesicle formation and protein sorting. Here we report a very rare case of HPS-2 who admitted because of fever.

Case Report A 5 months-old female patient admitted to our hospital because of fever. She is the first child of a consanguinous parents. She had mild facial dysplasia, whitish-yelllow hair and horizontal nystagmus. Opthalmological evaluation showed oculocutaneous albinism. Moderate hepatosplenomegaly was revealed. Anemia (Hb; $8.3 \mathrm{gr} / \mathrm{dl})$ and neutropenia $(0.4 \times 109 / \mu \mathrm{L})$ with normal platelet count were documented. Bone marrow aspiration yielded hemophagocytosis. Triglyceride, ferritin and fibrinogen levels were in normal limits. She was treated with proper antibiotic treatment and discharged to follow-up in outpatient clinic. Neutropenia was subsequently fluctuated. She had been hospitalized six more times due to febrile neutropenia and at each admission cytopenia including thrombocytopenia $(15 \times 109 / \mu \mathrm{L})$ in addition to hepatosplenomegaly were revealed. Time to time increased triglyceride levels were documented. All episodes were resolved with proper antibiotic and $\mathrm{r}-\mathrm{HuG}-\mathrm{CSF}$ treatment,. without requiring $\mathrm{HLH}$ treatment. Genetic analysis revealed homozygous nonsense mutation in exon 18 of the AP3B1 gene.

Conclusion Patients with albinism and opthalmological complaints should be evaluated for Hermansky-Pudlak syndrome.

\section{THALASSEMIA PREVENTATION AND ACTIVITY OF PEDIATRIC HEMATOLOGY AND ONCOLOGY DEPARTMENT AT BANGABANDU SHEIKH MUJIB MEDICAL UNIVERSITY IN BANGLADESH}

doi:10.1136/archdischild-2012-302724.0517

MdA Khaleque, G Hafiz, CS Huq Pavel. Pediatric Hematology-Oncology Dept., Bangabandu Sheikh Mujib Medical University, Dhaka, Bangladesh

Background and Aims Thalassemia is a genetic and crucial disease. Approximately 240 million peoples are suffering from this disease. Every year 10 million children are suffering from this disease. $\mathrm{Hb}-\mathrm{E}$ dieases is available in south east Asia, north east India and Bangladesh. Originalally $\mathrm{Hb}$-E disease is 5 times more than Beta Thalassemia in Bangladesh.

Method The outbreak of this disease is not calculated at this moment but carrier is 15 million. We are collected experimental data from 3 hundred voluntiers in our center. They have not family history of Thalassemia. In that experimental data Beta Thalassemia carrier $2.33 \%$ and $\mathrm{Hb}-\mathrm{E}$ Carrier $10 \%$. If we are experiment among the people who have history of Thalassemia, this disease is increased no doubt. This disease have actually no curable treatment except BoneMarrow tranplantation. Treatment cost is excessive and unbearable. Only time to time Blood transfusion and costly drug is given for the increasing of life span. Treatment cost of every $30 \mathrm{~kg}$ child need 4 lac taka every year. If 2 bag blood need every patient in every month, 1 lac 20 thousand bag blood will be need every month in Bangladesh. 